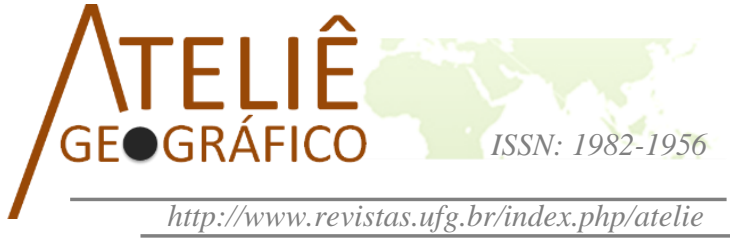

\section{A titulação coletiva de terras quilombolas e os conflitos por direitos territoriais no estado do Rio Grande do Norte, Brasil}

\author{
The collective titling of quilombola lands and the conflicts \\ for territorial rights in the state of Rio Grande do Norte, \\ Brazil
}

La titulación colectiva de tierras quilombolas y los conflictos por los derechos territoriales en el Estado de Río

Grande del Norte, Brasil

Camila da Silva Pereira

Universidade Federal do Ceará

camilasilvageo@gmail.com

\author{
Alexandra Maria de Oliveira \\ Universidade Federal do Ceará \\ alexandra.oliveira@ufc.br
}

\begin{abstract}
Resumo
A titulação coletiva das terras de comunidades remanescentes de quilombos tem se configurado em uma das políticas que representam a territorialização do poder do Estado e o exercício do poder pelos quilombolas. A proposta deste artigo é discutir a titulação coletiva de terras de remanescentes quilombolas, destacando os impasses, o andamento dos processos e os conflitos territoriais no Rio Grande do Norte. O período de análise dá-se a partir de 2003, ano de promulgação do Decreto 4.887, que regulamentou o direito e a titulação de terras quilombolas. Após pesquisa bibliográfica, coletamos dados secundários junto a órgãos federais e realizamos entrevistas semiestruturadas com lideranças quilombolas e com o antropólogo do Incra. Os resultados apontaram fatores que atrasam o andamento dos processos, como a burocracia e a escassez de recursos para a contratação de apoio técnico para o mapeamento das áreas e dos conflitos deflagrados tanto entre os próprios membros das comunidades como também entre esses membros e os sujeitos externos às comunidades que reivindicam lotes de terra em alguns territórios.
\end{abstract}

Palavras-chave: Titulação coletiva. Terras quilombolas. Rio Grande do Norte. 


\begin{abstract}
The collective titling of the lands which belong to the remnant communities of quilombos has been configured as one of the policies that represent the territorialization of the State power and the exercise of power by quilombolas. The purpose of this article is to discuss the collective titling of quilombola remnant lands, highlighting the impasses, the processes development and the territorial conflicts in Rio Grande do Norte. The period of analysis starts in 2003, when the Decree 4.887 was promulgated to regulate the right and title of quilombola lands, up to the current year. After bibliographic research, secondary data were collected from federal agencies and semi-structured interviews with quilombola leaders and the Incra anthropologist were performed. The results pointed to factors that delay the progress of the processes, such as bureaucracy and the lack of resources to hire technical support to map the areas and conflicts that have arisen both among the members of the communities themselves, as well as these members and external subjects to the communities who claim lots of land in some territories.
\end{abstract}

Keywords: Collective titling. Quilombola lands. Rio Grande do Norte.

\begin{abstract}
Resumen
La titulación colectiva de tierras de las comunidades remanentes de quilombos se ha configurado en una de las políticas que representan la territorialización del poder del Estado y el ejercicio del poder por parte de los quilombolas. Este artículo se propone discutir la titulación colectiva de las tierras remanentes de los quilombolas, destacando los impases de la comunidad, los procesos y los conflictos territoriales en Río Grande del Norte. El periodo de análisis se da a partir de 2003, año de la promulgación del Decreto 4.887, que reglamentó el derecho y la titulación de tierras quilombolas. Tras la investigación bibliográfica, se recolectaron datos secundarios junto con órganos federales y se realizaron entrevista semiestructuradas con los líderes quilombolas y el antropólogo del Incra. Los resultados apuntan a factores que retrasan la marcha de los procesos, como la burocracia y escasez de los recursos para la contratación de soporte técnico para el levantamiento de las áreas y los conflictos entre los propios miembros de las comunidades, como también entre las comunidades y sujetos externos que también reclaman lotes de tierra en algunos territorios.

Palabras Claves: Titulación colectiva. Tierras quilombolas. Río Grande del Norte.
\end{abstract}

\title{
Introdução
}

O caráter identitário dos grupos quilombolas no Brasil está relacionado às relações de poder no território, direcionando-nos a pensar o processo de politização dos territórios quilombolas. Nesses territórios, as relações de poder político têm a terra como base de difusão e representam um jogo de interesses múltiplos em que grupos quilombolas e o Estado configuram formas diferenciadas de exercício do poder, a partir do estreitamento de suas relações após a promulgação da Constituição Federal de 1988, que instituiu no art. 68 o direito à titulação coletiva das terras de remanescentes quilombolas.

As relações de poder são acionadas e fortalecidas numa ordem social localmente organizada, a qual Raffestin (1993, p. 158) denomina de "vivido territorial", 
composto pelos objetos e símbolos, e pelos valores que os sujeitos sociais atribuem a esses elementos na construção físico-social do território. Além disso, o poder diz respeito às relações econômicas e políticas, entendendo território como campo do exercício da política do Estado e dos interesses de controle dessa área geográfica. Resultam disso as múltiplas e coexistentes relações, tendo em vista que o território de atuação política estadual é o mesmo território do exercício do poder simbólico das relações sociais, dando significado às diversas formas de resistência e luta pela terra por parte dos remanescentes quilombolas. A política de titulação de terras de remanescentes quilombolas constitui uma das ações de reparação da histórica desigualdade no acesso à terra que caracterizou a colonização e o domínio do território brasileiro. Assim, é inevitável pensarmos nas políticas públicas agrárias sem recordarmos o histórico de desigualdade que culminou na organização de uma estrutura fundiária extremamente concentrada, sobretudo na região Nordeste (ANDRADE, 1986).

Resguardando a diversidade dos processos de territorialização negra e a formação de territórios quilombolas no Rio Grande do Norte, o artigo reflete sobre a política de titulação coletiva de terras de remanescentes quilombolas, destacando o andamento dos processos e os conflitos socioterritoriais entre os quilombolas e com outros agentes no estado.

São uma herança histórica os conflitos sociais com base no interesse pela terra no Brasil, destacando-se as mobilizações camponesas, os conflitos indígenas e, com demandas diferenciadas, a politização da terra pelas comunidades quilombolas. Atribuímos esse termo "politização" à discussão da terra para destacar seu valor político acentuado após os marcos jurídicos, principalmente a Constituição Federal de 1988, que modificaram o papel do Estado e os direitos e deveres da sociedade civil (MORAES, 1999).

A discussão proposta no artigo representa o desdobramento da trajetória de estudos e aproximação com comunidades quilombolas no estado do Rio Grande do Norte desde 2011. Na trajetória, vivenciando os territórios e compartilhando experiências com pesquisadores na área, pudemos transmitir neste trabalho nossas vivências com a natureza teórica do campo de estudo bem como com a natureza empírica, trazendo considerações sobre as relações de poder e os conflitos diversos que caracterizam os territórios quilombolas pesquisados.

Para tanto, a pesquisa bibliográfica, que embasa as reflexões, constrói-se a partir de autores como: Anjos (2004) e Arguedas (2013), para discutir acerca de comunidades quilombolas e o direito às terras tradicionalmente ocupadas; Haesbaert (2001, 2002, 2004), para refletir sobre os conceitos de território e territorialidade; Andrade (1986), para entender a estrutura agrária e a desigualdade no campo. Coletamos dados nos sites do Instituto Nacional de Colonização e Reforma Agrária (Incra), da Fundação Cultural Palmares (FCP), da Comissão Pró-índio de São Paulo (Cpisp) e da Secretaria de Política de Promoção da Igualdade Racial (Seppir). Realizamos entrevistas semiestruturadas com o antropólogo do Incra - RN responsável pelos processos de titulação no estado e com as lideranças quilombolas das comunidades com processo de 
titulação em estágio avançado: Acauã, no município de Poço Branco, e Boa Vista dos Negros, no município de Parelhas ${ }^{1}$.

A entrevista com o antropólogo abordou questões sobre o funcionamento da política de titulação de terras, a morosidade da concretização das etapas, a burocracia nas ações que dependem da natureza das terras ocupadas e as perspectivas de mudança na vida dos quilombolas com a efetivação da política.

As entrevistas com as lideranças quilombolas trataram sobre as dificuldades em declararem-se quilombolas em um contexto social racista, além de investigar as principais demandas de seus territórios e as perspectivas pós-titulação das terras.

Os dados primários produzidos por meio das entrevistas são apresentados e discutidos no corpo do texto por meio de fragmentos das falas dos participantes e de análise das declarações de maneira geral. Referimo-nos aos participantes pelas suas funções desempenhadas no Incra e nas comunidades mencionadas a fim de preservar suas identidades. Os dados secundários são expostos e discutidos no texto em forma de quadros e de um mapa de localização dos territórios quilombolas oficialmente reconhecidos no estado, destacando os que têm ou não processo aberto no Incra.

Entrevistamos representantes das comunidades de Acauã e Boa Vista dos Negros, pelo fato de que algumas outras também com processo de titulação avançado, no período de realização dos diálogos, não tinham agenda disponível para nos receber, como foram os casos de Macambira (com área territorial abrangida pelos municípios de Lagoa Nova, Bodó e Santana do Matos), Capoeiras (no município de Macaíba) e Jatobá (no município de Patu), sendo esta última a única comunidade titulada no estado do Rio Grande do Norte.

Problematizamos acerca do discurso hegemônico do Estado de que a política de titulação coletiva das terras de remanescentes quilombolas constitui uma forma de ressarcir esses grupos sociais e subsidiar a reprodução de suas relações, destacando que somente a titulação da terra não garantirá esse feito, sendo necessário assegurar a efetivação dos demais direitos previstos por sua condição cidadã, independentemente de sua autodeclaração como quilombolas.

$\mathrm{O}$ artigo está organizado em duas seções. Na primeira, discutimos o processo de legislação da terra, que regulariza a propriedade coletiva das comunidades quilombolas bem como as etapas que compõem a política de titulação e alguns dos seus impasses. Na segunda, debatemos sobre o andamento e a burocratização dos processos no estado do Rio Grande do Norte, alguns conflitos coletivos e os enfrentamentos das comunidades em defesa dos seus territórios.

\footnotetext{
${ }^{1}$ Ambas as comunidades são focos da pesquisa de doutorado iniciada em 2015. Além delas, as comunidades Macambira (situada nos municípios de Lagoa Nova, Bodó e Santana do Matos) e Jatobá (no município de Patu) compõem o universo de estudo da tese que considera as comunidades com processo de titulação avançado no Incra.
} 


\section{A questão quilombola e a normatização do acesso à terra: a burocratização dos processos}

A questão quilombola, em pauta nos debates acadêmicos, atinge diversos setores da sociedade. Isso contribui para a ampliação dessas discussões, favorecendo a abertura para a visão dos diferentes processos que resultaram na formação das comunidades quilombolas no Brasil, originalmente classificadas pelo Conselho Ultramarino de 1740 como "toda habitação de negros fugidos que passem de cinco, em parte despovoada, ainda que não tenham ranchos levantados nem se achem pilões neles" (SCHMITT; TURATTI; CARVALHO, 2002, p. 2). Essa conceituação durante muito tempo limitou a análise da diversificação de processos pelos quais algumas comunidades remanescentes quilombolas se formaram. Nas últimas décadas, estudiosos das Ciências Humanas têm ampliado as análises sobre as territorializações negras considerando, além dos processos de fuga, casos de "doações" de terras aos negros por serviços prestados, compra de terras por baixos preços, entre outros processos (ANJOS, 2009; RATTS, 2003).

O debate se expandiu tanto, nas últimas décadas, que vários autores utilizam diferentes termos para caracterizar os grupos quilombolas, tais como: comunidades negras rurais, comunidades quilombolas, terras de santo, territórios quilombolas, quilombos contemporâneos, territórios de pretos, territórios do povo negro ou comunidades remanescentes de quilombos (RATTS, 2000 e 2003; ANJOS, 2004).

No Brasil, grupos dessa natureza receberam inicialmente a nomenclatura de mocambos e, a partir de 1559, passaram a ser chamados de quilombos (THEODORO; MORAES; GOMES, 2016). Embora haja as terminologias anteriormente apresentadas, os termos quilombos, remanescentes de quilombos ou remanescentes quilombolas, do ponto de vista legislativo, são categorias jurídicas utilizadas pelo Estado brasileiro a partir da Promulgação da Constituição Federal de 1988 considerando elementos para sua identificação e titulação das terras, tais como: trajetória histórica própria, relações territoriais específicas e ancestralidade negra relacionada com o período escravocrata (INCRA, 2017).

A diversidade das denominações resulta do processo investigativo de pesquisadores ao longo das últimas décadas sobre as comunidades, bem como da conquista dos espaços pelos quilombolas ao declararem suas identidades a partir do (re)conhecimento de suas histórias. Esses espaços, acadêmicos e midiáticos, em grande maioria, foram conquistas mediadas, principalmente, pelas ações do Movimento Negro Unificado, que tiveram início na década de 1930. Mas foi em 1970 que o movimento começou a se reestruturar, quando representantes de várias entidades se reuniram em resposta à discriminação racial sofrida por quatro garotos do time infantil de voleibol do Clube de Regatas Tietê e à prisão, tortura e morte de Robison Silveira da Luz, acusado de roubar frutas numa feira (PEREIRA, 2008).

Além desses episódios, o aumento dos casos de racismo e assassinatos de negros nas principais capitais do Brasil suscitou mobilizações para a criação de um 
movimento que fosse representativo nos debates sobre a discriminação racial e, posteriormente, aliou-se à luta quilombola, mediando a reivindicação de suas demandas frente ao Estado. O Movimento Negro Unificado oficializou-se em 7 de julho de 1978, em meio à Ditadura Militar (PEREIRA, 2008).

Algumas das principais conquistas das lutas quilombolas, mediadas pelo Movimento Negro Unificado, foram a inserção das suas demandas territoriais na Constituição Federal de 1988. No Ato das Disposições Constitucionais Transitórias, o art. 68 determina: "aos remanescentes das comunidades dos quilombos que estejam ocupando suas terras é reconhecida a propriedade definitiva, devendo o Estado emitirlhes os títulos respectivos" (BRASIL/CF, 1988, p. 160). Em 2003, no governo do presidente Luiz Inácio Lula da Silva, é promulgado o Decreto 4.887 que atribui ao Incra e a FCP a responsabilidade dos procedimentos de identificação, reconhecimento, delimitação, demarcação e titulação das terras de remanescentes quilombolas. Atualmente, o Incra desenvolve políticas públicas de regularização fundiária e criação de assentamentos (PINTO, 2012), além de lidar diretamente com o processo de titulação das comunidades remanescentes de quilombos reconhecidas oficialmente pela FCP.

Embora a discussão tenha se ampliado e muitas comunidades tenham passado a entender sua ancestralidade, os direitos negados historicamente e aqueles adquiridos a partir do reconhecimento da dívida histórica com essas populações, ainda é comum comunidades rejeitarem essa identificação. Esse posicionamento pode se fundamentar na falta de articulação nas comunidades de entender os direitos enquanto coletivos e não individuais ou no racismo, que subjuga o sentido do que é ser quilombola e as denomina como oportunistas por utilizarem essa identidade para alcançar benefícios.

A propriedade coletiva das terras é um direito assegurado pela Constituição de 1988, mas ela enfrenta um arranjo burocrático lento e complexo que depende de uma série de fatores, inclusive da manifestação favorável por parte dos quilombolas.

Por se tratar de uma ação conjunta com o Incra, com a FCP e os governos municipal e estadual, a política de titulação de terras de quilombolas é extremamente burocrática em relação à forma de aquisição das terras brasileiras ao longo do tempo, o que dificulta o andamento dos processos. Vários sujeitos que representam o poder no território, em diferentes graus, estão envolvidos, a começar pelos quilombolas, já que o processo de titulação tem início a partir da autodeclaração de suas identidades na maior parte dos casos, devido à própria autonomia e consciência que algumas comunidades vêm ganhando ao longo do tempo. De acordo com Arguedas (2013, p. 16), o "processo de reconhecimento de um território e uma identidade configuram relações complexas e às vezes contraditórias e conflitantes".

Sobre a questão da autoatribuição étnica dos grupos quilombolas, destacamos a Ação Direta de Inconstitucionalidade (ADI) 3239 de 2004, desencadeada pelo antigo Partido da Frente Liberal, atual Democratas, contra o Decreto 4.887/2003 (CPISP, 2017). A ação questiona a constitucionalidade do decreto e o critério de autoatribuição no reconhecimento das comunidades, alegando que as informações fornecidas pelos 
quilombolas necessitam de marcos que as tornem objetivas e comprováveis, sobretudo o marco temporal, ou seja, a ação alega que somente devem ser reconhecidas quilombolas as comunidades com processo de formação anterior à abolição oficial do regime de escravidão (MANO, 2016).

A referida ação recentemente foi julgada pelo Supremo Tribunal Federal no dia 8 de fevereiro de 2018 e deu sentença favorável à constitucionalização do Decreto $4.887 / 2003$ e, portanto, aos procedimentos constantes nele para o reconhecimento e a titulação de terras de remanescentes quilombolas. A ação que tramitava desde 2012 configurava mais uma forma de retardar ou negar o direito desses povos, mantendo o poder dos latifundiários e das oligarquias políticas e econômicas. A votação a favor do povo quilombola representa uma conquista coletiva apoiada por vários movimentos sociais, sobretudo o Movimento Negro e Quilombola (ALMEIDA, 2018).

A visão engessada de que as comunidades devem permanecer e resguardar traços genuinamente africanos limita a análise dos modos de vida desses sujeitos, bem como das diferentes formas de aquisição e ocupação de suas terras, excluindo-os da dinâmica social que transforma todos os seus espaços, os seus locais de vivência e as suas relações de sociabilidade.

Os territórios quilombolas serão compreendidos através da discussão de Haesbaert (2001), que os considera a materialização de diversas relações de poder, tanto materiais quanto simbólicas. $\mathrm{O}$ autor destaca duas vertentes para entender o território: a vertente jurídico-política, na qual o Estado funciona como um instrumento de ordenamento das relações de poder e, portanto, do território como espaço onde elas (políticas públicas, em evidência) se materializam, e a vertente culturalista, estudada a partir da ligação simbólica e afetiva de um grupo com o seu espaço vivido.

Albagli (2004) comunga da ideia apresentada por Haesbaert, ao destacar que o território pode adquirir significados distintos a partir de variadas dimensões: sociopolítica, física, econômica e simbólica, dependendo de sua formação socioespacial.

Sem dúvida, a forma de legislar a questão fundiária no Brasil, após a Constituição de 1988, reforçou o caráter político do acesso à terra e do direito a sua propriedade, suscitando maior capacidade de mobilização dos sujeitos diretamente beneficiados pelas novas leis: quilombolas, ribeirinhos, indígenas, assentados rurais, entre outros. No entanto, o acesso aos direitos é dificultado pela burocracia do arranjo político brasileiro, no qual a elite política na maioria das vezes é também a elite agrária.

Uma das mudanças nos instrumentos de gestão e, consequentemente, nas políticas para os grupos quilombolas, foi a inserção das suas demandas no Plano Plurianual do período de 2012 a 2015 (BRASIL/PPA, 2014), de acordo com Verdum (2011), no qual constam o planejamento de orçamento e a gestão de recursos do governo federal. $\mathrm{O}$ plano divide-se em 65 programas temáticos, dos quais 16 fazem referência às ações para os territórios quilombolas no Brasil. As ações previstas no Programa Brasil Quilombola (PBQ) foram agregadas ao PPA, e, nesse contexto, as políticas públicas para os quilombolas mesclam-se com ações para outros grupos sociais historicamente 
marginalizados. Apresentamos na Figura 1 as principais etapas do processo para a titulação dos territórios quilombolas no Brasil.

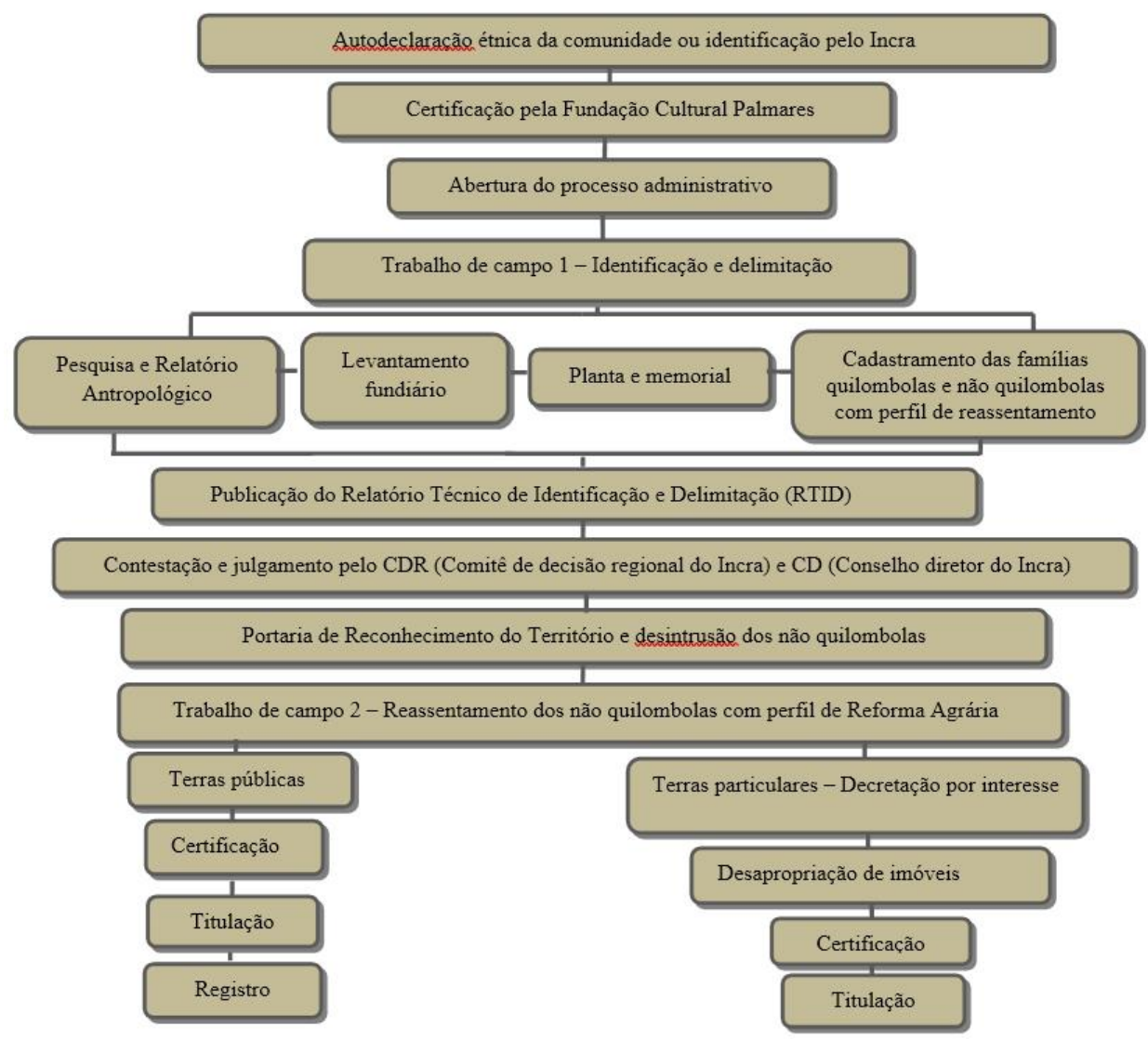

Figura 1: Resumo das etapas do processo de titulação.

Fonte: Diagnóstico do PBQ (2012), Cpisp (2018) e Incra (2018).

Merece destaque a fase da elaboração do Relatório Técnico de Identificação e Delimitação (RTID), com todas as informações sobre: população; aspectos físicos do local; levantamento fundiário; decreto de desapropriação dos imóveis. De acordo com informações do Incra (2015),

Em sendo terras da União, esta será titulada pelo Incra ou pela Secretaria do Patrimônio da União. Em sendo terras estaduais ou municipais, a titulação cabe ao respectivo ente da federação. Por outro lado, no caso da área quilombola estar localizada em terras de domínio particular é necessário que o Presidente da República 
emita um Decreto de Desapropriação por Interesse Social de todo o território, a partir do qual será aberto procedimento judicial de desapropriação e indenização do(s) proprietário(s) (INCRA, 2015, p. 01).

Sobre as desapropriações para titulação coletiva de terras, destacamos a situação das comunidades cujos processos de titulação caminharam até a etapa de pagamento de indenizações aos ocupantes não quilombolas nos territórios: Jatobá; Acauã; Boa Vista dos Negros; Capoeiras; Macambira. Com exceção de Jatobá, que já se encontra titulada, as demais comunidades estão nessa etapa, considerada pelo Incra como uma das mais demoradas, pois demanda negociação com posseiros e fazendeiros e o pagamento das indenizações por parte da União ou dos Estados.

Segundo documentos disponibilizados pelo antropólogo do Incra, a comunidade Acauã reivindicava 201 hectares do proprietário da Fazenda Maringá, mas a ação foi perdida no Supremo Tribunal Federal sem chance de recurso. As demais terras já foram desapropriadas, com exceção de uma área de posseiro com cerca de 28 hectares, ainda em tramitação. Em Macambira, o processo também está avançado, apesar das pendências judiciais advindas de conflitos entre a comunidade e um fazendeiro local que cedeu terras ainda não desapropriadas para a instalação de eólicas da empresa (Gestamp) em meados de 2013. As tensões entre comunidade, fazendeiro e empresa foram, compulsoriamente, resolvidas através de acordo administrativo no qual a comunidade perdeu mais de 600 hectares para o empreendimento.

Ainda sobre a comunidade Acauã, destacamos o processo de reterritorialização (HAESBAERT, 2002) pelo qual os moradores passaram na década de 1950. As transformações socioespaciais na realidade local tem nas obras de construção da barragem Engenheiro José Batista do Rego Pereira, conhecida também como açude Poço Branco, em meados de 1959, o evento de maior impacto no cotidiano dos moradores. Com essas obras, o rio Ceará-Mirim teve seu nível aumentado significativamente, o que ocasionou o projeto de realocação das famílias que viviam às margens do rio, como os povoados denominados de Contador e a antiga comunidade de Acauã (VALLE, 2006).

A promessa de que a obra favoreceria a continuidade das atividades agrícolas nas imediações da barragem, utilizando o reservatório para manter as vazantes, não se cumpriu, trazendo uma série de problemas aos moradores, sobretudo de ordem cultural e econômica (FUNDO BRASIL DE DIREITOS HUMANOS, 2012). A desreterritorialização (HAESBAERT, 2004) das famílias deixou uma herança de incertezas e negação de seus direitos básicos que ainda acompanham o cotidiano dos moradores de Acauã, que vivem atualmente em cerca de 540 hectares, mas na época de realocação, devido às obras da barragem, receberam cerca de 4 hectares de terra cedidas pela prefeitura de Poço Branco sem que lhes fossem fornecidas as condições básicas ao atendimento de suas necessidades. A comunidade é a segunda com processo de titulação coletiva das terras em fase de finalização, depois da comunidade Jatobá. 
Essas são algumas das tensões territoriais que também contribuem para a morosidade no andamento dos processos, que, uma vez finalizados, tornam a terra inalienável e de propriedade coletiva da comunidade (INCRA, 2017).

Estar entre os territórios reconhecidos não garante de fato os direitos dessas comunidades, visto que muitas delas não têm acesso aos direitos básicos: água, educação e saúde. De acordo com o documento do PBQ (2012), apesar da existência e extensão da bibliografia no campo jurídico, antropológico, histórico e geográfico sobre comunidades quilombolas no Brasil, o tema da regularização fundiária para essas comunidades conta com uma gama de argumentos que invocam o desconhecimento e a insegurança jurídica, fatores que dificultam a garantia da propriedade coletiva para a defesa da manutenção de seus territórios, que perdura desde meados do século XIX, quando foi sancionada a Lei de Terras em 1850.

\section{A titulação das terras quilombolas no estado: andamento e impasses nos processos}

Estudos de Cavignac et al. (2006 e 2007), Morais (2005) e Valle (2006), entre outros, investigaram a importância do trabalho escravo negro no Rio Grande do Norte e na constituição dos territórios quilombolas reconhecidos hoje no estado. Recentemente apropriamo-nos da obra Lima (1988) que faz um resgate das formas de entrada da mão de obra negra no estado, dos principais locais de sua territorialização, de como tal processo foi determinado pelas relações sociais de trabalho e de como o negro foi integrado à sociedade após a abolição da escravatura. Como ocorreu em outros estados, os negros viram-se desolados e à margem da ressignificação das relações sociais de produção, classificados como vadios e convivendo com as diversas formas de discriminação racial e social.

Desde 2003, ano de publicação do Decreto 4.887, das 1.715 comunidades com processo de titulação aberto no Incra, cerca de 120 foram tituladas (INCRA, 2018). Conforme a FCP (2018), entre os anos de 2004 e 2017 foram certificadas 3.051 comunidades em todo o Brasil, tendo sido emitidas 2.547 certidões de reconhecimento para abertura de processo de titulação no Incra.

Nesse contexto, há uma disparidade significativa entre a quantidade de certidões emitidas em relação ao número de processos abertos no Incra, pois somente 1.715 das 2.547 comunidades com certidões expedidas estão com processos abertos, boa parte deles estancados no referido órgão.

O estancamento nas ações de titulação impossibilita em níveis diferenciados o acesso e a garantia de reprodução e permanência dos quilombolas em suas terras ancestrais. Uma realidade ainda mais inquietante é que, de acordo com o Incra (2017), os territórios quilombolas até então titulados abrangia $0,12 \%$ do território nacional. Estimase que a titulação de todos os quilombos do Brasil não abrangerá $1 \%$ das terras, enquanto os demais estabelecimentos agropecuários representam cerca de $40 \%$ do território nacional (ARGUEDAS, 2014). 
Atualmente, são vinte e três territórios reconhecidos enquanto quilombolas no Rio Grande do Norte, vinte deles com processo aberto no Incra. A Figura 2 apresenta a localização dos territórios quilombolas no estado do Rio Grande do Norte, os anos de abertura dos processos e as comunidades que ainda não tiveram acesso a essa política.

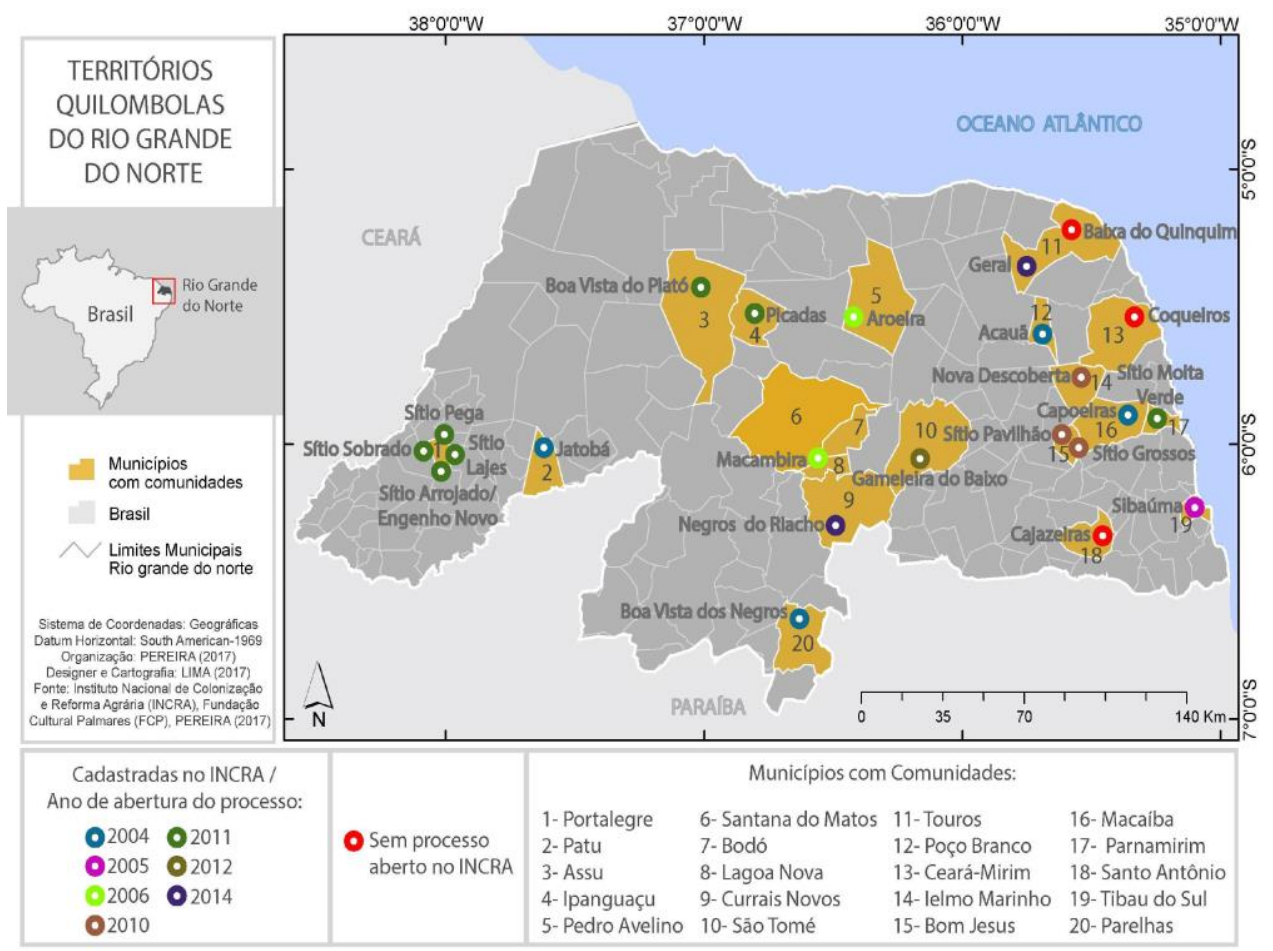

Figura 2: Territórios quilombolas no estado do Rio Grande do Norte.

Fonte: Incra (2018); FCP (2018). Elaborado pela autora.

O quadro 1 apresenta as comunidades com processo em andamento e a única comunidade titulada no estado.

Quadro 1: Comunidades com processo em andamento no Incra e comunidade titulada - RN

\begin{tabular}{|c|c|c|c|c|}
\hline Comunidade & Município de Localização & Área/ha & Número de Famílias & Etapa do processo \\
\hline Acauã & Poço Branco & 540,5138 & 47 & CDRU \\
\hline Aroeiras & Pedro Avelino & 530,8024 & 37 & RTID \\
\hline $\begin{array}{c}\text { Boa Vista dos } \\
\text { Negros }\end{array}$ & Parelhas & 445,2676 & 36 & Decreto no DOU \\
\hline Capoeiras & Macaíba & 906,7744 & 232 & Decreto no DOU \\
\hline Jatobá & Patu & 219,1934 & 18 & Titulado \\
\hline Macambira & $\begin{array}{c}\text { Lagoa Nova, Santana do } \\
\text { Matos e Bodó }\end{array}$ & $2.589,1695$ & 263 & RTID \\
\hline Sítio Pavilhão & Bom Jesus & 52,1668 & 23 & \\
\hline
\end{tabular}

Fonte: INCRA. Andamento dos processos - quadro geral (2018). 
Para a explicação das etapas apresentadas no quadro destacamos que a etapa Concessão de Direito Real de Uso (CDRU) do processo da comunidade Acauã corresponde à concessão de uso de parte das terras reivindicadas pela comunidade, tendo em vista que outra parte das terras ainda não foi desapropriada para fins de titulação. Os RTIDs identificados nas comunidades Pavilhão e Aroeiras referem-se à etapa de mapeamento da área, construção do relatório antropológico e análise da situação jurídica das terras. Os Decretos de desapropriação publicados no Diário Oficial da União (DOU) nos processos das comunidades Capoeira e Boa Vista dos Negros determinam a desintrusão das terras e a indenização aos não quilombolas ocupantes (ainda em tramitação). A Portaria no DOU no processo da comunidade Macambira delimita as áreas reconhecidas como propriedade das comunidades.

Os territórios que não se enquadram no que descrevemos no quadro 1 não apresentam avanços processuais significativos. Conforme o antropólogo do Incra, as disparidades entre a quantidade de processos abertos no Incra e aqueles que estão em andamento justificam-se pela falta de recursos financeiros para dar prosseguimento às etapas de monitoramento, avaliação dos processos, visitas técnicas e mapeamento dos territórios. As dificuldades em campo também retardam o andamento da elaboração dos RTID's, destacando-se: perda de documentos, registros históricos da formação dos territórios e discrepância na oralidade entre os quilombolas. $\mathrm{O}$ antropólogo complementa relatando que:

O problema não reside somente no fato de não ter relatório antropológico feito, pois muitas comunidades têm relatório e não têm processos caminhando. Mas aqui no Rio Grande do Norte, todas que têm relatório estão com processo encaminhado. Os recursos destinados para regularização quilombola, hoje, deve totalizar em torno de 24 mil reais para o ano inteiro, inviabilizando um pouco cobrir todo o estado. Mas o pior problema é que tem setores dentro do Incra que não introjetaram a política quilombola como sua atribuição legítima. Além disso, as organizações associativas das comunidades ainda se apresentam muito fragmentadas, e não há uma agenda conjunta com demandas comuns. (Entrevista realizada em março de 2018 no Incra, Natal $\mathrm{RN})$.

Embora haja um esforço das lideranças e dos demais quilombolas, ainda há dificuldades de organização dentro das próprias comunidades em construir um discurso que fortaleça a busca por seus direitos territoriais, conforme aponta a liderança da comunidade Boa Vista dos Negros:

A associação da comunidade Boa Vista dos Negros é comandada por mulheres há bastante tempo e foi fundada em 1993, e nesse enfrentamento começamos a entender o que é ser quilombola e os conflitos que acompanham a declaração dessa identidade. Os principais desafios que encontro é o racismo institucional em nível municipal e estadual; não temos condições de ter advogado que nos 
informe e nos direcione na busca de todos os nossos direitos. A falta de capacitação para nós que estamos à frente da comunidade é um fator que dificulta a busca por nossos direitos. Com relação aos conflitos de interesses que interferem na nossa organização, realmente nem todos concordam com a forma de trabalhar. Mas eu não diria que temos conflitos, a gente tem discordância de ideias, que é comum a outras comunidades. (Entrevista realizada em abril de 2018 na comunidade Boa Vista dos Negros, em Parelhas - RN).

A líder quilombola de Boa Vista acrescenta que o fortalecimento das identidades e da luta coletiva é um trabalho contínuo e desafiador, pois as dificuldades de declarar-se negro e quilombola no Brasil torna o processo complicado, mesmo que os moradores conheçam os direitos que lhes são garantidos por lei. As lideranças reconhecem o papel fundamental das instituições de ensino e de órgãos que tratam da questão quilombola no Brasil e no estado, no diálogo sobre a história e a memória coletiva como elementos de fortalecimento e reconhecimento das identidades.

A liderança quilombola de Acauã apontou processos semelhantes aos da comunidade Boa Vista dos Negros, mas destaca que a negação e o desconhecimento da identidade quilombola são muito mais frequentes entre os adolescentes e jovens da comunidade que migram para a cidade de Poço Branco para estudar e enfrentam uma série de preconceitos. A liderança afirma:

São muitos desafios frente à coordenação da associação, a falta de recursos e apoio para o melhoramento da escola da comunidade e outras coisas que precisamos. Outra dificuldade é se assumir quilombola. Hoje a gente trabalha com as crianças na escola da comunidade para que eles cresçam entendendo o que é ser quilombola, mas ainda existe preconceito e ainda vai existir por muito tempo e isso dificulta eles se entenderem e assumirem a identidade, pois sofrem muito racismo e preconceito, já que os outros de fora da comunidade não entendem o que é ser quilombola (Entrevista realizada em abril de 2018 na comunidade Acauã, em Poço Branco - RN).

A fragilidade no conhecimento e a negação dessa identidade são frutos da herança histórica de segregação social e racial em virtude do estigma do passado de escravidão. Conforme Munanga (2004), a inferioridade étnica com base na construção social e política da ideologia da existência de "raças", como maneira de tornar socialmente desiguais pessoas de origens étnicas diferentes, exerce influência em dois movimentos que estão ligados aos direitos dos grupos quilombolas. De um lado, essa discriminação pode estimular a rejeição à declaração de ser quilombola e, de outro, pode influenciar na articulação dos grupos e no fortalecimento da declaração e do conhecimento dessa identidade, que, na maioria dos casos, necessita de um processo de mediação das instituições de ensino e dos movimentos sociais.

Uma realidade frequente em muitas comunidades no Brasil é a migração dos quilombolas, principalmente os mais jovens, em busca de trabalho em outros municípios e/ou regiões do país, conforme relatos de quilombolas de algumas comunidades visitadas 
no Rio Grande do Norte. De acordo com Scarlato (2011) e Turra Neto (2001), os movimentos migratórios causam tanto uma ruptura do sujeito com o seu lugar de origem quanto o seu processo de reintegração em um novo ambiente com costumes diferenciados, sem que necessariamente todas as relações pré-construídas sejam anuladas.

Além do fator socioeconômico que ocasiona a busca por oportunidades de trabalho em outros espaços, outros fatores ocasionam as fragmentações nas relações comunitárias e o enfraquecimento da conscientização de seus direitos. Em visitas às comunidades Pêga e Arrojado, no município de Portalegre, moradores afirmaram desconhecer o critério de escolha dos representantes da comunidade e acreditar que a mesma possivelmente tenha tido influências políticas. Os moradores relataram que nada do que é discutido nas reuniões que ocorrem na capital do estado, juntamente com o Incra, é repassado às comunidades. Essa fragmentação na comunicação dentro das comunidades, mencionada também pelo antropólogo do Incra, demonstra os microconflitos e as relações de poder existentes nas comunidades.

Outro impasse para o andamento dos processos é a oposição de alguns quilombolas à titulação para não abrir mão de suas propriedades particulares em favor do uso coletivo. É o caso da comunidade quilombola Sibaúma, situada em Tibau dos Sul, no litoral sul do estado, em área de especulação imobiliária e de expansão do turismo. Conforme Cavignac et al. (2006, p. 281), "os moradores têm grande dificuldade em fazer exercício de cidadania que lhes é ofertado repentinamente, relutam em mudar de uma lógica de pequenos proprietários para uma outra, desta vez coletiva".

O posicionamento desses moradores pode ser explicado pela construção ideológica da terra como um reserva de valor e/ou reserva patrimonial (OLIVEIRA, 2001), bem como pode fazer referência ao fato de que, na maioria das vezes, essas terras são herdadas e adquirem um valor parental que, material e/ou simbolicamente, se perderia pelo uso coletivo. Cavignac et al. (2006, p. 282) aponta que na comunidade de Sibaúma "alguns quilombolas adotaram sem hesitação uma outra lógica, a do lucro individual, e abandonaram progressivamente os valores coletivos ligados à terra e ao seu cultivo".

O processo que ocorre em Sibaúma desdobra-se em outros territórios, inclusive de outros estados, a exemplo da comunidade quilombola Cumbe, situada no município de Aracati, no litoral cearense. A comunidade tradicionalmente sobrevivia da pesca de peixes e de caranguejos feita por homens e da mariscagem, pelas mulheres. Em 1990, a carcinicultura chega à comunidade como alternativa de emprego e renda fixa diferentemente da prática da agricultura e da pesca nos rios e mangues. De acordo com Aguiar e Souza (2017, p. 07-08): “a maioria dos habitantes foi convencida a aceitar o desmatamento do mangue e a retirada da vegetação para a construção das estruturas de tanques".

Além desse impacto econômico e ambiental, em 2008 chega à comunidade um empreendimento de energia eólica ocasionando uma série de conflitos, mudança na 
paisagem e restrições aos moradores no uso de parte das terras. Assim, a comunidade hoje encontra-se dividida entre os declarantes quilombolas e os não quilombolas. Estes últimos, em grande parte, trabalham nas empresas de carcinicultura e a veem como uma atividade que lhes garante a sobrevivência. Em contrapartida, o despejo dos nutrientes dos tanques de criação de camarão no mangue ocasiona a morte da biodiversidade, que também é campo de trabalho e fonte de renda dos moradores do Cumbe (AGUIAR; SOUZA, 2017).

Conflitos semelhantes e outros embates se produzem a partir das relações de poder nos territórios entre quilombolas e não quilombolas. A questão da terra para produzir (individual ou coletivamente) é o elemento comum entre todos. Na fala do antropólogo, é destacada a importância da terra enquanto base para o cultivo dos alimentos da comunidade e para a continuação das famílias nas terras. Segundo ele, é necessário também que as políticas e os programas já existentes sejam efetivados, sobretudo os que tratam de segurança alimentar para aquelas populações que vivem em regiões de chuvas irregulares. Os projetos não chegam a ser concretizados nos territórios por uma série de burocracias internas, além de serem insuficientes para suprir as necessidades do quantitativo de comunidades quilombolas e para subsidiar sua capacidade produtiva, variável de uma região para outra (ISOLDI; SILVA, 2009).

As lideranças quilombolas de Boa Vista dos Negros e Acauã destacam que, em geral, as políticas públicas para os quilombolas estancaram e os territórios pouco recebem assistência de saúde, segurança alimentar e educação. Com relação à educação, comunidades como Boa Vista dos Negros, Pêga, Arrojado, entre outras, não têm escolas locais. As escolas, quando presentes, apresentam estrutura precária e poucas condições de manutenção para uma formação de qualidade, como é o caso da escola de Acauã.

$\mathrm{Na}$ fala das lideranças, a terra titulada traz a esperança do uso coletivo do espaço para o plantio das culturas, além da perspectiva de receber projetos de irrigação que mantenham a produção de alimentos em períodos de irregularidade de chuvas e a garantia de posse contra a apropriação ilegal de posseiros e fazendeiros.

O território, visto para além da questão da terra, é o elemento mais importante para essas comunidades, rurais e urbanas, pois ele é a base para a continuação das famílias e para a reprodução das relações sociais, culturais, econômicas e ambientais.

\section{Considerações Finais}

O percurso teórico e metodológico aqui apresentado revelou, minimamente, a amplitude da questão quilombola e as relações de poder nos seus campos territorial e jurídico. $\mathrm{O}$ entendimento acerca das comunidades remanescentes de quilombos requer aprofundamento histórico, político e cultural para não incorrer em reducionismos conceituais que, muitas vezes, limitam a complexidade das relações que dinamizam os territórios. 
O debate construído sobre tais comunidades não visou indagar a respeito das suas identificações, colocando-as em dúvida ou generalizando o fato de que, por haver direitos, todos podem querer se declarar quilombolas. Essa autodeclaração tem um sentido histórico e um impacto social que mudam consideravelmente a condição cidadã de quem a faz. Assim, considerar que esses grupos irão se autodeclarar somente para conseguir direitos é simplificar a política de reconhecimento oficial e a titulação de terras, que têm seus critérios de inclusão, bem como descaracterizar a luta quilombola e as memórias de quem assume essa ancestralidade.

Embora tenhamos apresentado o passo a passo da política de titulação de terras de remanescentes quilombolas, vimos que, na prática, ela funciona de acordo com as especificidades dos territórios e das relações que os dão sentido. Os conflitos de interesses internos aos grupos e aqueles produzidos com ocupantes não quilombolas determinam o fluxo das ações da política e compõem o arranjo burocrático de seu funcionamento.

As expectativas quanto às mudanças nas condições de vida nos territórios apontam as esperanças de melhorias e a segurança de ter terra para plantar em maior escala, mas as lideranças têm clareza de que essa transformação não é imediata e que a política tem seus limites de abrangência, como os têm outras ações governamentais. Os posicionamentos contrários à identificação quilombola e à titulação representam o desafio principal para os que estão à frente das associações, pois, embora seja natural haver discordâncias na vivência da comunidade, a fragmentação do senso de coletivo dificulta o fortalecimento dos grupos na busca por seus direitos territoriais. Além disso, apontam vários mecanismos de defesa dos sujeitos quilombolas que, por outro lado, temem ficar à margem das demais políticas após terem a principal delas conquistada: a propriedade coletiva das terras.

Os processos e níveis de conscientização dos sujeitos são variáveis e se fazem mais fortes, ou não, se compararmos a outras realidades, por uma série de fatores, que vão desde os processos de mediação de reconhecimento de sua história e os direitos a serem assegurados até fatores de ordem política local que, em muitos casos, exercem influência nas formas de manifestação de poder dos grupos.

Essa política, mesmo funcionando como uma forma de controle do território pelo Estado, constitui uma medida reparadora da desigual apropriação e distribuição de terras no Brasil, de fundamental importância na territorialidade desses grupos, que têm nos seus territórios o principal elemento de sustentação para a busca por justiça social.

\section{Referências Bibliográficas}

AGUIAR, I. T.; SOUSA, L. G. de. Os impactos territoriais da reestruturação produtiva no litoral leste do Ceará: o caso da comunidade do Cumbe. ENCONTRO NACIONAL DA REDE OBSERVATÓRIO DAS METRÓPOLES. Natal, RN. 2017. Anais. Universidade Federal do Rio Grande do Norte. p. 01-12. 
ALBAGLI, S. Território e territorialidade. In: LAGES, V.; BRAGA, C.; MORELLI, G. (Orgs.). Territórios em movimento: cultura e identidade como estratégia de inserção competitiva. Rio de Janeiro: Relume Dumará/ Brasília, DF: SEBRAE, 2004, p. 25-69.

ALMEIDA, E. M. de. Propriedade definitiva aos quilombolas é correção histórica. Folha de São Paulo, 10/02/2018. Disponível em:

<https://www1.folha.uol.com.br/poder/2018/02/propriedade-definitiva-aos-quilombolas-ecorrecao-historica.shtml>. Acesso em: 28 mar. 2018.

ANDRADE, M. C. de. A terra e o homem no Nordeste: contribuição ao estudo da questão agrária no Nordeste. 5. ed. São Paulo: Atlas, 1986.

ANJOS, R. S. A. dos. Quilombos: geografia africana - cartografia étnica - territórios tradicionais. Brasília: Mapas Editora \& Consultoria, 2009.

ANJOS, R. S. A. dos. Cartografia e cultura: territórios dos remanescentes de quilombos no Brasil. VIII Congresso Luso-Afro-Brasileiro de Ciências Sociais: a questão social no novo milênio. Set. 2004.

ARGUEDAS, Alberto Gutiérrez. Território para viver: dinâmicas territoriais da comunidade quilombola de Acauã. Dissertação (Mestrado) - Universidade Federal do Rio Grande do Norte. Centro de Ciências Humanas, Letras e Artes. Programa de Pós-Graduação em Geografia. Natal, RN. 2014. 200 f.

ARGUEDAS, A. G. A comunidade quilombola de Acauã (Rio Grande do Norte) e sua luta pelo território tradicional. VI SIMPÓSIO INTERNACIONAL DE GEOGRAFIA AGRÁRIA - VII SIMPÓSIO NACIONAL DE GEOGRAFIA AGRÁRIA. João Pessoa, PB. Anais. 2013. ISBN: 978-85-237-0718-7.

BRASIL. Constituição da República Federativa do Brasil de 1988. Documento atualizado. 2016. Brasília, DF. Disponível em:

<https://www2.senado.leg.br/bdsf/bitstream/handle/id/518231/CF88_Livro_EC91_2016.pdf >. Acesso em: 20 jun. 2018.

BRASIL. Decreto $n^{\circ} 4.887$, de 20 de novembro de 2003. Brasília, DF. 2003. Disponível em: <http://www.planalto.gov.br/ccivil_03/decreto/2003/d4887.htm>. Acesso em: 20 out. 2017.

BRASIL. PPA (2012 - 2015) - Caderno de monitoramento do PPA. Brasília, DF. 2014. Disponível em: <http://bibspi.planejamento.gov.br/handle/123456789/44>. Acesso em: 27 nov. 2017.

CAVIGNAC, J. A.; MELO, J. A. F. de; RODRIGUES JUNIOR, G. J.; SANTOS, S. G. dos. Relatório Antropológico da Comunidade Quilombola de Boa Vista dos Negros - RN. Convênio UFRN/INCRA-RN. Natal, RN 2007.

CAVIGNAC, J. A.; LINS, Cyro Holando de Almeira; MOREIRA, Stéphanie Campos Paiva; MAUX, Augusto Carlos de Oliveira. Uma Sibaúma só! Relatório antropológico da comunidade quilombola de Sibaúma (RN). Convênio UFRN/INCRA-RN. Natal, RN. 2006. 
CPISP - Comissão Pró-índio de São Paulo. Ação Direta de Inconstitucionalidade $N^{\circ} 3.239$ 9/600 - Brasília, DF. 2017. Disponível em:

<http://www.cpisp.org.br/acoes/upload/arquivos/Parecer\%20-\%20ProcuradorGeral\%20da\%20Rep\%C3\%BAblica.pdf>. Acesso em: 26 nov. 2017.

CPISP - Comissão Pró-índio de São Paulo. O caminho da titulação (2018). Disponível em: <http://www.cpisp.org.br/terras/html/comosetitula_caminho.aspx>. Acesso em: $20 \mathrm{dez}$. 2017.

FCP - Fundação Cultural Palmares. Certidões expedidas às comunidades remanescentes de quilombos. Brasília, DF. 2018. Disponível em: <http://www.palmares.gov.br/wpcontent/uploads/2013/06/1-crqs-certificadas-ate-10-06-2013.pdf>. Acesso em: 20 jan. 2018.

FUNDO BRASIL DE DIREITOS HUMANOS. Associação dos Moradores do Quilombo de Acauã- AMQA. Rio Grande do Norte: Natal, RN. 2012. Disponível em:

$<$ http://www.fundodireitoshumanos.org.br/v2/pt/projects/view/associacao-dos-moradores-doquilombo-de-acaua-amqa-rio-grande-do-norte>. Acesso em: 30 nov. 2017.

HAESBAERT, R. O mito da desterritorialização: do "fim dos territórios" à multiterritorialidade. Rio de Janeiro: Bertrand Brasil, 2004.

HAESBAERT, R. Territórios alternativos. Niterói: Eduff; São Paulo: Contexto, 2002.

HAESBAERT, R. Território, cultura e des-territorialização. In: ROSENDAHL, Z; CORRÊA, R. L. (Orgs.). Religião, identidade e território. Rio de Janeiro: Ed UERJ, 2001, p. 115-144.

INCRA - Instituto Nacional de Colonização e Reforma Agrária. Andamento dos processos quadro geral. Brasília, DF. 2018. Disponível em:

$<$ http://www.incra.gov.br/sites/default/files/incra-andamentoprocessosquilombolas_quadrogeral.pdf >. Acesso em: 24 jan. 2018.

INCRA - Instituto Nacional de Colonização e Reforma Agrária. Regularização de território quilombola: perguntas e respostas. Brasília, DF. 2017. Disponível em:

$\langle$ http://www.incra.gov.br/sites/default/files/incra-perguntasrespostas-a4.pdf $>$. Acesso em: 05 nov. 2018.

INCRA - Instituto Nacional de Colonização e Reforma Agrária. Quadro atual da política de regularização de territórios quilombolas no Incra. Brasília, DF. 2015. Disponível em: $<$ http://www.incra.gov.br/sites/default/files/uploads/estruturafundiaria/quilombolas/passo_a_passo_atualizado_pdf.pdf>. Acesso em: 30 nov. 2017.

ISOLDI, I. A.; SILVA, C. L. da. O espaço territorial como referência para a construção da cidadania: uma reflexão geográfica introdutória sobre o problema das demarcações de terras de populações "remanescentes". Ateliê Geográfico. Goiânia, GO v. 3, n. 1, p. 30 - 43, abr. 2009.

LIMA, J. A. de. A escravidão negra no Rio Grande do Norte. Natal: Coleção de informação de massa, 1988. 
MANO, M. K. Numa canetada, o recuo de 15 anos na política de terras quilombolas. Jornal Carta Capital, 17/05/2016. Disponível em:

$<$ https://www.cartacapital.com.br/sociedade/numa-canetada-o-recuo-de-15-anos-na-politicade-terras-quilombolas>. Acesso em: 20 jan. 2018.

MORAIS, G. C. de O. Entre parentes: cotidiano, religiosidade e identidade na serra de Portalegre/RN. Dissertação de Mestrado do Programa de Pós-Graduação em Ciências Sociais da UFRN. Natal, RN, 2005. $160 \mathrm{f}$.

MORAES, J. D. de. A função social da propriedade e a Constituição Federal de 1988. São Paulo: Milheiros Editores, 1999.

MUNANGA, K. Rediscutindo a mestiçagem no Brasil: identidade nacional versus identidade negra. Belo Horizonte: Autêntica, 2004.

OLIVEIRA, A. U. A longa marcha do campesinato brasileiro: movimentos sociais, conflitos e Reforma Agrária. Revista Estudos Avançados. São Paulo, USP, v.15, n. 43, p. 185-206. 2001.

PEREIRA, A. M. Trajetória e perspectivas do Movimento Negro Brasileiro. Belo Horizonte: Nandyala, 2008.

PINTO, S. R. Políticas públicas e desigualdades sociais. Brasília: Paralelo 15, 2012.

PBQ - Programa Brasil Quilombola. Diagnóstico de Ações Realizadas. Secretaria de Política de Promoção da Igualdade Racial - SEPPIR. Brasília, DF. 2012. Disponível em:

<http://www.seppir.gov.br/portal-antigo/destaques/diagnostico-pbq-agosto >. Acesso em: 20 nov. 2017.

RAFFESTIN, C. O que é território? In: RAFFESTIN, C. Por uma geografia do poder. São Paulo: Ática S.A. 1993, p. 143-163.

RATTS, A. Geografia entre as aldeias e os quilombos: territórios etnicamente diferenciados. In: RATTS, A. (Org.). Geografia: leituras culturais. Goiânia: Alternativa, 2003, p. 29-48.

RATTS, A. O mundo é grande e a nação também: identidade e mobilidade em territórios negros. Tese de Doutorado em Ciência Social (Antropologia Social). Universidade de São Paulo, USP, Brasil, 2000.

SCARLATO, F. C. População e urbanização brasileira. In: ROSS, J. L. S. (Org.). Geografia do Brasil. São Paulo: Editora da Universidade de São Paulo, 2011, p. 383-463.

SCHMITT, A.; TURATTI, M. C. M.; CARVALHO, M. C. P. de. A atualização do conceito de quilombo: identidade e território nas definições teóricas. Ambiente \& Sociedade - Ano V $-\mathrm{n}^{\mathrm{o}}$ 10. $1^{\text {o }}$ Sem, p. 01-06. 2002.

THEODORO, G.; MORAES, W.; GOMES, F. Dos quilombos ao quilombismo: por uma história comparada da luta antirracista no Brasil (notas para um debate). Revista da Associação Brasileira de Pesquisadores/as Negros/as (ABPN), [S.1.], v. 8, n. 18, p. 215-238, fev. 2016. ISSN 2177-2770. 
TURRA NETO, N. Enterrado, mas ainda vivo!: Identidade punk e território em Londrina. Dissertação de Mestrado. Universidade Estadual Paulista Faculdade de Ciências e Tecnologia. Campus de Presidente Prudente - São Paulo, 2001. 179 f.

VALLE, C. G. O. do. A comunidade quilombola de Acauã Cunhã, Cunhã Velha, Rio Grande do Norte - Estudo antropológico. UFRN, Natal, 2006.

VERDUM, R. Terras e territórios quilombolas no PPA (2012-2015), 28/08/2011. Disponível em: <http://www.inesc.org.br/biblioteca/textos/terras-e-territorios-quilombolasno-ppa-2012-2015>. Acesso em: 10 mar. 2018.

*Os autores agradecem a Coordenação de Aperfeiçoamento de Pessoal de Nível Superior-Capes, pela concessão de bolsa de estudo à primeira autora período de 2015 e 2016 .

\title{
Camila da Silva Pereira
}

Doutoranda em Geografia na Universidade Federal do Ceará, mestra em Geografia pela Universidade Federal do Rio Grande do Norte e licenciada em Geografia pela Universidade do Estado do Rio Grande do Norte. Atualmente é Professora Assistente no Curso de Geografia da Universidade Estadual do Ceará, no Campus da Faculdade de Filosofia Dom Aureliano Matos (Fafidam/Uece). Membro do Grupo de Pesquisa NATERRA - Campo, Terra e Território da Universidade Estadual do Ceará, vinculado ao Conselho Nacional de Desenvolvimento Científico e Tecnológico CNPq.

Rua Sabino Maciel Júnior, 58. Condomínio Solar das Palmeiras, apto. 107, B1. C. Cep: 59.628-782. Mossoró - RN.

E-mail: camilasilvageo@gmail.com

\begin{abstract}
Alexandra Maria de Oliveira
Doutora em Geografia pela Universidade de São Paulo, mestra em Geografia pela Universidade Federal de Sergipe e graduada em Geografia pela Universidade Federal do Ceará. Atualmente é Professora Associada do Departamento de Geografia da UFC, onde atua no Programa de Pós-Graduação em Geografia. Bolsista Capes na função de orientadora no Programa Residência Pedagógica Subprojeto Geografia UFC.

Rua Saldanha Marinho, 750. Cep: 60.040-280. Fortaleza - CE.

E-mail: alexandra.oliveira@ufc.br
\end{abstract}

Recebido para publicação em abril de 2018

Aprovado para publicação em dezembro de 2018 